\title{
Lion hunting behaviour and vegetation structure in an African savanna
}

\author{
Scott R. Loarie ${ }^{\mathrm{a}, *}$, Craig J. Tambling ${ }^{\mathrm{b}, \mathrm{c}, 1}$, Gregory P. Asner ${ }^{\mathrm{a}, 2}$
}

a Department of Global Ecology, Carnegie Institution for Science, Stanford, CA, U.S.A.

b Mammal Research Institute, Department of Zoology and Entomology, University of Pretoria, Pretoria, South Africa

c Centre for African Conservation Ecology, Department of Zoology, Nelson Mandela Metropolitan University, Port Elizabeth, South Africa

Emerging evidence suggests that male lions are not dependent on female's hunting skills but are in fact successful hunters. But difficulty locating kills and objectively characterizing landscapes has complicated the comparison of male and female lion hunting strategies. We used airborne Light Detection and Ranging (LiDAR) measurements of vegetation structure in Kruger National Park, combined with global positioning system (GPS) telemetry data on lion, Panthera leo, kills to quantify lines-of-sight where lion kills occurred compared with areas where lions rested, while controlling for time of day. We found significant differences in use of vegetation structure by male and female lions during hunts. While male lions killed in landscapes with much shorter linesof-sight $(16.2 \mathrm{~m})$ than those in which they rested, there were no significant differences for female lions. These results were consistent across sizes of prey species. The influence of vegetation structure in shaping predator-prey interactions is often hypothe-sized, but quantitative evidence has been scarce. Although our sample sizes were limited, our results provide a mechanism, ambush hunting versus social hunting in the open, to explain why hunting success of male lions might equal that of females. This study serves as a case study for more complete studies with larger samples sizes and illustrates how LiDAR and GPS telemetry can be used to provide new insight into lion hunting behaviour.

Keywords:

Bayesian statistics

Carnegie Airborne Observatory GPS telemetry

LiDAR

lion

Panthera leo

predator-prey interaction vegetation structure

With large mammals increasingly confined to protected areas (Ceballos et al. 2005; Karanth et al. 2010), understanding how to maintain landscape-scale ecological processes that support diverse mammal communities within reserve boundaries is a critical conservation priority (Woodroffe \& Ginsberg 1998; Bengtsson et al. 2003; Berger 2004; van Aarde \& Jackson 2007; Loarie et al. 2009a, b). Sustainable predator-prey interactions exemplify con-ditions that are difficult to achieve within protected areas (Sinclair et al. 2003, 2008; Tambling \& Du Toit 2005; Ripple \& Beschta 2006; Hayward \& Somers 2009). Pressure to offer charismatic viewing opportunities to tourists (Hutton \& Leader-Williams 2003; Lindsey et al. 2007) has led many small reserves to reintroduce lions, Panthera leo, as exemplified by Slotow \& Hunter's (2009) study of lion introductions into 37 small reserves across South Africa. Despite being indigenous to most of these reserves, lions are returning to very different landscapes, namely those that are increasingly being fenced and fragmented with altered hydrological and fire regimes (Loarie et al. 2009a).

\footnotetext{
* Correspondence: S. R. Loarie, Department of Global Ecology, Carnegie Institution for Science, 260 Panama Street, Stanford, CA 94305, U.S.A. E-mail address: loarie@stanford.edu (S. R. Loarie).

1 E-mail address: cjtambling@zoology.up.ac.za (C. J. Tambling).

2 E-mail address: gpa@stanford.edu (G. P. Asner).
}

Sustaining predator-prey interactions within these protected areas will require a better understanding of how spatial heterogeneity influences predation strategies. Several recent studies have begun to explore the role of spatial heterogeneity in shaping the distribution of predator-prey interactions across landscapes (Hopcraft et al. 2005; Valeix et al. 2009). For example, the decline of roan, Hippotragus equinus, and other antelope that tolerate sparse surface water to avoid high predator densities has been partially attributed to lions following water-dependent antelope into arid landscapes after the construction of waterholes (Grant et al. 2007; Hayward et al. 2007). How spatial heterogeneity in vegetation structure influences predator-prey interactions is less well understood. Several studies suggest that predator ambush opportunities provided by vegetation structure could shape the distribution and foraging behaviour of herbivores across a landscape, but quantitative data are scarce (Hopcraft et al. 2005; Fischhoff et al. 2007; Valeix et al. 2009). Such interactions between vegetation structure and predation would be significant because vegetation structure is readily manipulated by park managers through fire, elephant, Loxodonta africana, exclusion and other controls (Asner et al. 2009; Levick et al. 2009). Understanding possible feedbacks between vegetation structure and predation success may elucidate both unintended consequences of and opportunities arising from management activities. 
Testing for the influence of vegetation structure on predatorprey interactions has been complicated by two factors. First, most studies locate predation sites by following predators that are difficult to observe in dense vegetation (Funston et al. 2001), especially at night when most hunting occurs (Mills \& Biggs 1993), and thus, are potentially biased by sampling along roads and in the presence of observers. We apply global position sys-tem (GPS) telemetry for an unbiased sampling of predator loca-tions across heterogeneous landscapes. Second, vegetation structure influences ambush opportunities through the local viewshed (i.e. the distance travelled by lines-of-sight from a location before they become obstructed). Because viewsheds are difficult to quantitatively measure in the field, ad hoc data on shrub and grass cover are used as proxies for lines-of-sight. Alternatively, vegetation has been ignored, with viewsheds characterized only from coarse topographic features such as rock kopjes and canyons (Hopcraft et al. 2005). We used LiDAR data to model how vegetation structure and other fine-scale landscape structures shape viewsheds consistently and objectively across the study area.

Lions are of particular interest because of their strong sexual dimorphism in both appearance and behaviour. Although male lions were generally thought to be less accomplished hunters than females (Scheel \& Packer 1991; Stander 1992), recent research suggests that males successfully kill as frequently as females (Funston et al. 2001). Funston et al. (2001) found that prey species largely explained differences between male and female hunting behaviour. These authors found no consistent influence of vegetation structure, probably because of the difficulties of monitoring lion hunting behaviour, as mentioned above.

Here, we combined fine-scale airborne Light Detection and Ranging (LiDAR) measurements with locations of lion predation events from Kruger National Park (KNP) in South Africa. From these data, we formulated a probabilistic model to quantify how vegetation structure shapes the viewsheds used by the lions. Importantly, our Bayesian framework allowed us to propagate uncertainty from lines-of-sight to viewsheds and to consider the impact of sample size. We then tested for the influence of lion sex, lion hunting or resting behaviour and prey size on lions' viewshed choices.

\section{METHODS}

\section{Telemetry and Field Data}

We collected GPS telemetry and kill data from lions in the Satara region of KNP $\left(24^{\circ} 00^{\prime} 00^{\prime \prime}-24^{\circ} 30^{\prime} 00^{\prime \prime} \mathrm{S}, 31^{\circ} 30^{\prime} 00^{\prime \prime}-32^{\circ} 00^{\prime} 00^{\prime \prime} \mathrm{E}\right)$. Between May 2005 and April 2007, seven lions (five female and two males) were captured using standard SAN-Parks lion capture procedures (Smuts et al. 1977) and collared with GPS mobile communication (GSM) units (i.e. GPS/GSM, GPS units with mobile phone capabilities; Hawk105 units, African Wildlife Tracking, Pretoria, South Africa). A total of 15 collars set to record positions on one of two schedules were deployed across the seven lions during the course of the study. Collars were either set to record GPS coordinates once per hour for $24 \mathrm{~h}$ per day (seven collars), or set to record a GPS coordinate once per hour between 1800 and 0600 hours and then again at 0900, 1200 and 1500 hours (eight collars). The recording schedule was adjusted during the sampling period because the second schedule reduced the battery usage and focused on periods when lions are active (Hayward \& Slotow 2009). A comparison between the two schedules showed that there was no difference in the ability to locate kills (Tambling et al. 2010). Likewise, there was no effect of vegetation density on the success of GPS acquired locations. Using the remotely accessed movement data from the GPS collars, clusters of GPS positions where lions were stationary for more than $2 \mathrm{~h}$ were identified as potential resting or kill sites. GPS clusters were investigated on foot to determine the activity at each GPS cluster (Tambling et al. 2010).

We identified kills by the presence of stomach contents that were usually accompanied by carcass remains (bones, hair, horns or teeth). The stomach contents were chosen as diagnostic of the kill site because, while lions may move the carcass from the kill site (Schaller 1972), at Kruger, the stomach contents are almost always deposited within a few metres of the kill site (P. Funston, personal communication). This explains why stomach contents were occasionally separated from other carcass remains. Although we assumed that the stomach content location was the site where the kill was made, we accommodated potential movement of the carcass (before the stomach contents were emptied) in our analysis by propagating a $10 \mathrm{~m}$ radius around the location.

If no stomach contents or other carcass remains were found, we assumed the lions were resting in unfavourable conditions to initiate a hunt or perhaps recovering from a failed hunting attempt. To minimize the incidence of failing to detect carcass remains, and thereby misidentify kill locations as resting locations, we restricted our analysis to clusters checked within 16 weeks of their occurrence. After this period of time, success in detecting kills decreases (Tambling et al. 2010).

\section{LiDAR Data}

We mapped $100 \mathrm{~km}^{2}$ in the Satara region of KNP with the Carnegie Airborne Observatory (CAO) (Asner et al. 2007), an integrated LiDAR and hyperspectral system, in April/May 2008. The CAO LiDAR subsystem provides three-dimensional structural information of vegetation canopies and the underlying terrain surface. The GPS-IMU subsystem provides three-dimensional position and orientation data for the CAO sensors, allowing for highly precise and accurate projection of LiDAR observations on the ground. For this study, the CAO data were collected from $2000 \mathrm{~m}$ above ground level, providing maps of ground elevation, woody canopy height and three-dimensional structure at $1.12 \mathrm{~m}$ spatial resolution. LiDAR measurements were field-validated in May 2008 (Asner et al. 2009; Levick et al. 2009).

The LiDAR coverage overlapped with 300 lion clusters (66 kill and 234 rest locations). While the vegetation structure undoubtedly changed during the 1-3 year lag between the lion kill data and the LiDAR data, we assumed that, because woody biomass accounts for $63 \%$ of the Kruger landscape (Biggs et al. 2003), the general structure of the vegetation would be unchanged. Likewise, the density of seasonally varying vegetation, such as leaves, is roughly proportional woody vegetation (Lefsky et al. 1999). Lastly, while a dry year may result in uneven grazing pressure, the average enhanced vegetation index (EVI) for the study years was within one standard deviation of variation in EVI across the 10 -year period from 2002 through 2012.

Using the LiDAR data, we modelled the viewshed by calculating 72 lines-of-sight radiating outward horizontally from the lion clusters $1 \mathrm{~m}$ above ground level at $5^{\circ}$ increments where $1 \mathrm{~m}$ approximates the height of the lion's head. Lines continued until they intersected the woody canopy height or ground surfaces. If a lineof-site extended beyond the LiDAR data without intercepting an obstacle, it was excluded from analyses. Repeating all analyses using an alternative height of $0.5 \mathrm{~m}$ did not affect the results.

\section{Modelling Framework}

In our modelling framework, we envisioned lion characteristics such as sex, behaviour and prey size to be independent 
variables that drive decisions to choose certain landscapes. As such, we modelled the viewshed of a chosen location as a dependent variable driven by the behaviour and characteristics of the lion.

Consider a lion located in a landscape, $i$. We considered these locations to be independent since they were widely separated temporally and geographically. Let $\boldsymbol{y}_{\boldsymbol{i}}$ be a length $m$ vector of linesof-sight in metres radiating out horizontally from location $i$, each $1 \mathrm{~m}$ above the ground, angled at $5^{\circ}$ intervals $360^{\circ}$ around the animal. We assumed that each line-of-sight was independent since it travelled in a unique direction. Each line-of-sight ended when it intersected a barrier. Thus, the values in $\boldsymbol{y}_{\boldsymbol{i}}$ would be smaller in a densely vegetated landscape with a shorter viewshed than in an open landscape. The likelihood for how far each of the $j$ lines-ofsight travel, $\boldsymbol{y}_{\boldsymbol{i}}$, was assumed to be exponential,

$$
p\left(\boldsymbol{y}_{\boldsymbol{i}} \mid \lambda_{i}\right)=\prod_{j=1}^{m} \operatorname{Exp}\left(y_{i, j} \mid \lambda_{i}\right)
$$

The parameter $\lambda_{i}$ (summarizing the viewshed) has units of metres $^{-1}$ such that large $\lambda$ shortens the distances that lines-of-sight travel. The exponential distribution is a preferred method for modelling waiting times, such as the length of time until a phone rings, which is analogous to the distance that a ray travels before hitting a barrier modelled here. For all $n$ locations, the likelihood of the entire $n \times m$ data set $\boldsymbol{y}$ is therefore

$$
p(\boldsymbol{y} \mid \lambda)=\prod_{i=1}^{n}\left(\prod_{j=1}^{m} \operatorname{Exp}\left(y_{i, j} \mid \lambda_{i}\right)\right)
$$

To accommodate GPS error or the possibility that a carcass was dragged, we introduced uncertainty in the locations of our observations, $\boldsymbol{y}$. To do this, we randomly sampled 100 locations within $10 \mathrm{~m}$ of each observed location $i$ to make a set, $\left[z_{i}\right]$, of vectors of lines-of-site. We then considered $\boldsymbol{y}$ to be the vector of lines-of-sight from each unobserved 'true' kill location estimated from the observed set of possibilities, $\left[z_{i}\right]$. We assumed each member of the set had equal probability

$p\left(y_{i} \mid\left[z_{i}\right]\right)=\frac{1}{100}$

Across the $n$ lion locations, the viewsheds may vary. We therefore fitted a separate parameter $\lambda_{i}$ at each location. But to accommodate the landscape-level structure among locations, we used a hierarchical approach rather than treating each $\lambda_{i}$ as completely independent (Clark 2006). Bayesian statistics provide a powerful framework for building and estimating parameters from hierarchical models (Clark 2005; Clark \& Gelfand 2006). We modelled landscape-level structure in $\lambda_{i}$ with a gamma distribution

$\operatorname{Gam}\left(\lambda_{i} \mid \alpha, \beta\right)$

We chose a gamma distribution because it is the conjugate prior to the exponential distribution. According to Bayes' rule, the posterior probability of the parameters conditioned on the data is proportional to the likelihood of the data conditioned on the parameters multiplied by the prior probabilities for the parameters (Gelman et al. 1995). For prior probabilities, we used a gamma density on parameter $\beta$ and an exponential density on parameter $\alpha$ with hyperparameters $c, d$ and $e$ such that

$$
\begin{aligned}
& p(\beta)=\operatorname{Gam}(\beta \mid c, d) \\
& p(\alpha)=\operatorname{Exp}(\alpha \mid e)
\end{aligned}
$$

The joint posterior probability of the parameters conditioned on the data can be written

$$
\begin{aligned}
& p(\lambda, \alpha, \beta, y \mid[z]) \infty \prod_{i=1}^{n}\left(p\left(y_{i} \mid\left[z_{i}\right]\right) \prod_{j=1}^{m} \operatorname{Exp}\left(y_{i, j} \mid \lambda_{i}\right)\right) \prod_{i=1}^{n} \operatorname{Gam}\left(\lambda_{i} \mid \alpha, \beta\right) \\
& \quad \times \operatorname{Gam}(\beta \mid c, d) \operatorname{Exp}(\alpha \mid e)
\end{aligned}
$$

Gibbs sampling (Clark 2006) allowed us to estimate parameters from this high-dimensional posterior probability distribution by separately sampling from low-dimension conditionally independent probabilities. A conjugacy can then be used to directly sample for $\lambda$ and $\beta$ as follows

$$
\begin{aligned}
& \operatorname{Gam}\left(\lambda_{i} \mid \alpha+m, \beta+\sum_{j=1}^{m} y_{i, j}\right) \\
& \left.\operatorname{Gam} \beta \mid c+\alpha n, d+\sum_{i=1}^{n} \lambda_{i}\right)
\end{aligned}
$$

We used a Metropolis-Hastings step (Clark 2006) to sample for $\alpha$. We sampled 10000 iterations after a 500 iteration burn-in period. We chose prior values of $1 \times 10^{-5}, 5 \times 10^{-6}$ and 100 for hyperparameters $c, d$ and $e$, which were flat over reasonable domains for the parameters.

\section{Model Selection Framework and Controlling for Shade}

To test whether characteristics such as time of day, lion sex, lion behaviour or prey type influenced the viewsheds that lions chose to occupy, we used a model selection framework. In general, we estimated parameters for a simple 'one-size-fits-all' model as well as a more complex model with different parameters for different groups. We compared these models by calculating a $P$ value derived from a likelihood ratio test. If the more complex model represented a significant improvement over the simpler model, we concluded that the groups differed (Clark 2006).

To illustrate this framework, we grouped locations by time of day ( $6<t \leq 18$ or otherwise, where $t$ indicates hour) to test whether daytime shade resources influenced the selection of viewsheds. First, we grouped lion locations by time of day: daytime, $\eta$, or not, $v$. As above, we estimated $p\left(\lambda_{\eta}, \alpha_{\eta}, \beta_{\eta} \mid \lambda_{v}\right)$ and $p\left(\lambda_{v}, \alpha_{v}, \beta_{v} \mid \lambda_{v}\right)$, then calculated the likelihood ratio, LR (Table 1 , LR $1 /(2 \times 3)$ )

$$
\mathrm{LR}=\frac{p([z] \mid y, \lambda, \alpha, \beta)}{p\left([z] \mid y_{\eta}, \lambda_{\eta}, \alpha_{\eta}, \beta_{\eta}, y_{v}, \lambda_{v}, \alpha_{v}, \beta_{v}\right)}
$$

We then calculated deviance used for the hypothesis test, where $D(\theta)=-2 \ln L R$, distributed as approximately $\chi^{2}$ with degrees of freedom equal to the difference in the number of parameters (in this case, 2).

The above analysis revealed that lions were in landscapes with longer lines-of-sight during daytime (see Results). We were primarily interested in how hunting behaviour influences the selection of viewsheds, but correlations with shade resources complicated interpretation of these daytime patterns. For comparisons of lion behaviour, lion sex and prey size, we therefore removed all locations from daytime. Since lions rely on vision for nocturnal hunting, we assumed that viewsheds were meaningful at night (Elliott et al. 1977).

\section{Influence of Behaviour, Sex and Prey Size on Viewshed Choices}

Using the same model selection framework described above, we examined whether the viewsheds of locations that lions chose 
varied with lion behaviour (killing or resting) or lion sex. By estimating parameters by groups and performing likelihood ratio (LR) tests, we examined whether behaviours (Table 2 , LR $1 /(2 \times 3)$ ) or sexes (Table 2, LR $1 /(4 \times 5)$ ) of lions differed, whether killing behaviour (Table 2, LR 2/(6×7)) or resting behaviour (Table 2, LR 3 / $(8 \times 9)$ ) varied by lion sex, and whether the behaviour of male (Table 2 , LR $4 /(6 \times 8)$ ) and female (Table 2 , LR $5 /(7 \times 9)$ ) lions differed.

We then used published body masses of prey species (Smith et al. 2003) to examine whether the results differed when we grouped prey as 'small' ( $<100 \mathrm{~kg}$; Aepyceros melampus, Phacochoerus africanus, and Struthio camelus) o r 'large' $(>100$ kg; Tragelaphus strepsiceros, Connochaetes taurinus, Kobus ellipsi-prymnus, Equus quagga, Syncerus caffer, Giraffa camelopardalis, and Loxodonta africana) (Table 2). We used the average of male and female weights and $96.50 \mathrm{~kg}$ for Struthio camelus (Davies \& Bertram 2003). With the next heaviest prey type, Kobus ellipsiprymmus, weighing $210 \mathrm{~kg}, 100 \mathrm{~kg}$ was a natural break between the weights of the prey species and conformed to Funston et al.'s (2001) usage of size.

\section{RESULTS}

In our model of the landscape, the distances that lines-of-sight travel as they radiate outward from a location without intersecting an obstacle are dictated by the parameter $\lambda$ with units of $\mathrm{m}^{-1}$ (Fig. 1). Locations with large $\lambda$ can therefore be interpreted as shortening the extent of the viewshed. In our simplest model with all locations combined, $\lambda$ was distributed by $\operatorname{Gam}(\alpha, \beta)$ with mean parameter estimates of $\alpha=0.36$ and $\beta=1.71$. Accordingly, lines-ofsight averaged $\beta / \alpha=1 / \lambda=4.7 \mathrm{~m}$.

Average lines-of-sight for lion locations during the day $(2.6 \mathrm{~m})$ were significantly lower than those at other times of day $(8.1 \mathrm{~m})(P$ $<0.001$; Table 1 , LR $1 /(2 \times 3)$, Fig. 2$)$.

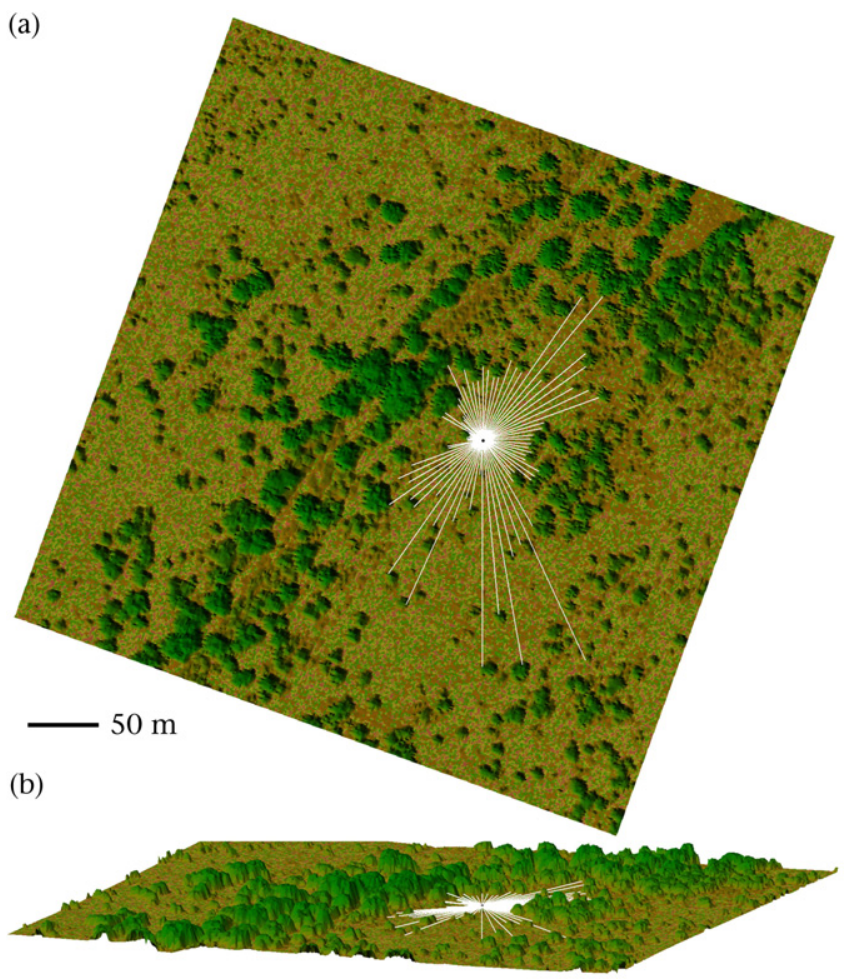

Figure 1. Airborne LiDAR and modelling indicates lines-of-sight (white) radiating outward in $5^{\circ}$ increments $1 \mathrm{~m}$ above ground level from GPS lion locations used to characterize each viewshed.
Next, we excluded the daytime locations and used the remaining $n=199$ night-time locations. Without controlling for sex, night-time behaviour had a slight significant influence on the viewsheds that lions selected $(P=0.01$; Table 2 , LR $1 /(2 \times 3))$, and lions killed at locations with lines-of-sight averaging $6.1 \mathrm{~m}$ and they rested in more open locations with lines-of-sight averaging $9.4 \mathrm{~m}$ (Fig. 3).

Without controlling for behaviour, night-time locations chosen by male and female lions were similar, both choosing locations with lines-of-sight averaging $8.3 \mathrm{~m}(P=0.06$; Table 2 , LR $1 /(4 \times 5))$. However, there were highly significant differences in the viewsheds of resting $(19.6 \mathrm{~m})$ and killing $(3.4 \mathrm{~m})$ male lion locations $(P<<0.001$; Table 2 , LR $4 /(6 \times 7))$. In contrast, there was no differ-ence between the viewsheds of resting $(8.3 \mathrm{~m})$ and killing $(8.6 \mathrm{~m})$ female lion locations $(P=0.59$; Table 2 , LR $5 /(8 \times 9))$.

These results were robust, controlling for large and small prey sizes. Locations where male lions killed both small $(5.72 \mathrm{~m}, P<<$ 0.001; Table 2, LR $1 /(2 \times 3)$ ) and large $(5.25 \mathrm{~m}, P=0.01$; Table 3, LR $1 /(4 \times 5))$ prey had shorter lines-of-sight than locations where they rested. In contrast, lines-of-sight distances at locations where female lions killed both small $(10.5 \mathrm{~m}, P=1$; Table 3 , L R 6 / $(7 \times 8))$ and large $(8.81 \mathrm{~m}, P=0.08$; Table 3 , LR $6 /(9 \times 10))$ prey did not differ significantly from those at locations where they rested.

\section{DISCUSSION}

Since lions are strongly sexually dimorphic, both physically and behaviourally, it might be expected that their hunting strategies and abilities differ. Male lions, which are thought to hunt less cooperatively than females, have generally been regarded as less successful than their female counterparts (Scheel \& Packer 1991). However, recent studies revealing that males are as capable as females in their hunting skills are changing these attitudes. It remains unclear how male lions compensate for their lack of cooperation to achieve the same success as females (Funston et al. 1998).

Funston et al. (2001) found that differing prey choice explains much of the differences in male and female hunting behaviour, and other studies have emphasized the role of prey choice in shaping lion hunting success (Hayward \& Kerley 2005; Owen-Smith \& Mills 2006, 2008). Funston et al. (2001) noted that male lions tend to hunt impala in landscapes with long grass and dense shrubs, but found no general patterns of vegetation structure on male lion hunting success. The authors acknowledged that their study was not well suited to identifying the role of vegetation structure because of the possibility for observer bias in dense landscapes. Similar observer bias may explain why earlier studies perceived male lions as less successful hunters than females. Before the availability of GPS telemetry, lion kills had to be located through field searches alone. Studies of lion kills were easier to do in open habitats such as the Serengeti and Etosha (Scheel \& Packer 1991; Stander 1992).

While GPS telemetry allowed us to control for observer bias, metadata on hunts collected by observers was unavailable. We do not know, for instance, whether carcasses were dragged from the kill sites or how many individual lions participated in the hunts. Our results were robust and significant despite propagating uncertainty (from up to $10 \mathrm{~m}$ of carcass dragging prior to evisceration) into our estimates. Multiple individual lions at a hunt would only impact our results if mixed-sex hunting groups were common. In southern Kruger, mixed-sex hunting groups accounted for less than $3 \%$ of 210 observed kills (Funston et al. 2001). Likewise, the presence of mixed-sex hunting groups would tend to diminish the differences between sexes, which were pronounced in our results.

In addition to incorporating carcass dragging uncertainty into the model, the likelihood ratio tests accommodated uncertainty of 
Table 1

Estimates of parameters influencing the viewshed of locations chosen by lions grouped by time-of-day

\begin{tabular}{|c|c|c|c|c|c|c|c|c|c|c|c|}
\hline \multirow[t]{2}{*}{ Index } & \multirow[t]{2}{*}{ Time-of-day } & \multirow[t]{2}{*}{$n$} & \multicolumn{2}{|l|}{$\alpha$} & \multicolumn{2}{|l|}{$\beta$} & \multirow[t]{2}{*}{$\beta / \alpha(\mathrm{m})$} & \multirow[t]{2}{*}{$\ln \mathrm{L}$} & \multirow[t]{2}{*}{ LR } & \multirow[t]{2}{*}{ Dev } & \multirow[t]{2}{*}{$P$} \\
\hline & & & Mean & $\mathrm{CI}$ & Mean & $\mathrm{CI}$ & & & & & \\
\hline 1 & Both & 300 & 0.36 & $0.31-0.42$ & 1.71 & $1.22-2.33$ & 4.73 & -79080 & $1 /(2 \times 3)$ & 95 & $8 \mathrm{E}-21^{*}$ \\
\hline 2 & Day & 101 & 0.4 & $0.3-0.52$ & 1.04 & $0.6-1.67$ & 2.62 & -20879 & & & \\
\hline 3 & Night & 199 & 0.39 & $0.31-0.47$ & 3.13 & $2.03-4.54$ & 8.12 & -58154 & & & \\
\hline
\end{tabular}

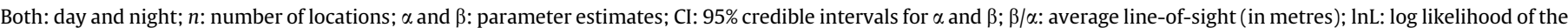
data; LR: probabilities of likelihood ratios used to compare likelihoods by index; Dev: deviance. Asterisks indicate groups that were significantly different.

small sample sizes. The significance of our results despite these uncertainties lends support to our conclusions that, for the individual lions analysed, differences were robust with the caveat that the differences in lion behaviour, lion sex and prey type refer only to night-time hunting. Our treatment of uncertainty, however, does not remedy the fact that we draw our conclusions from a small number of individual lions from the Satara region of Kruger National Park. Caution must be taken when considering whether conclusions from such a small sample of individuals can be generalized to other populations and landscapes. Indeed, with density estimates of seven to eight lions per $100 \mathrm{~km}^{2}$ across the northern basalts around Satara (Ferreira \& Funston 2010), in the most conservative sense these patterns may only apply to the study area. Because of these small sample sizes, we recommend that these results be viewed more as a case study to motivate larger-scale studies rather than as a broad generalization of lion hunting behaviour.

Given the small sample size, the consistent results across large and small prey types revealed that differing male and female hunting strategies are general and not dependent on prey size. For the male lions, the utility of ambush strategies across small and large prey types might be expected. Buffalo, Syncerus caffer, for example, are thought to be more vulnerable to predation in dense bush (Hay et al. 2008), and male lions are known to take a variety of prey types (Radloff \& Du Toit 2004). Perhaps our most surprising result, therefore, was that the female lions did not share this utilization of dense vegetation. If coordinating cooperative hunts on mid-sized prey is a successful female lion strategy (Funston et al. 1998; Owen-Smith \& Mills 2008), then it is possible that dense vegetation interferes with this hunting strategy. In any case, our results add the use of vegetation structure to a list of general factors including prey choice and the degree of cooperative behaviour that distinguishes male and female lion hunting strategies. It is likely that specializing in utilizing vegetation structure for ambush strategies contributes to male lions' success as hunters.

Our results confirm that lions sought out locations with short lines-of-site during the day. We assume that a preference for shade drives this selection, because of the largely nocturnal hunting strategy of lions (Mills \& Biggs 1993; Slotow \& Hunter 2009). But regardless of the mechanism, we were careful to control for the possible confounding influence of shade by removing daytime locations from the analyses. It is interesting that male lions tended to rest in much more open areas than females. We calculated the average length of viewsheds within home ranges by averaging viewshed length for 1000 random points within he minimum convex polygon encompassing all telemetry locations for each lion. The average viewshed lengths of home ranges were similar for both for male $(7.5 \mathrm{~m})$ and female $(7.2 \mathrm{~m})$ lions. This means that both sexes had similar opportunities to choose between densely vege-tated and more open landscapes. That the male lions' resting lo-cations and home ranges were more open than those of females may suggest that factors other than hunting contribute to male lions' choice of home ranges. Perhaps intimidating potential competitors and spotting females or prey contribute. Hopcraft et al. (2005) suggested that lions use vantage points such as kopjes with large viewsheds to find carcasses, and that resting in open landscapes may help them spot scavenging opportunities. But, because we excluded midday locations, the influence of shade cannot explain these results.

The role of vegetation structure in predator-prey interactions is not immediately intuitive. For prey, the risk of being ambushed is greater in landscapes with dense vegetation, but so is the ability to hide (Wronski et al. 2006). Fischhoff et al. (2007) proposed that zebras' avoidance of open habitat when lions are active suggests
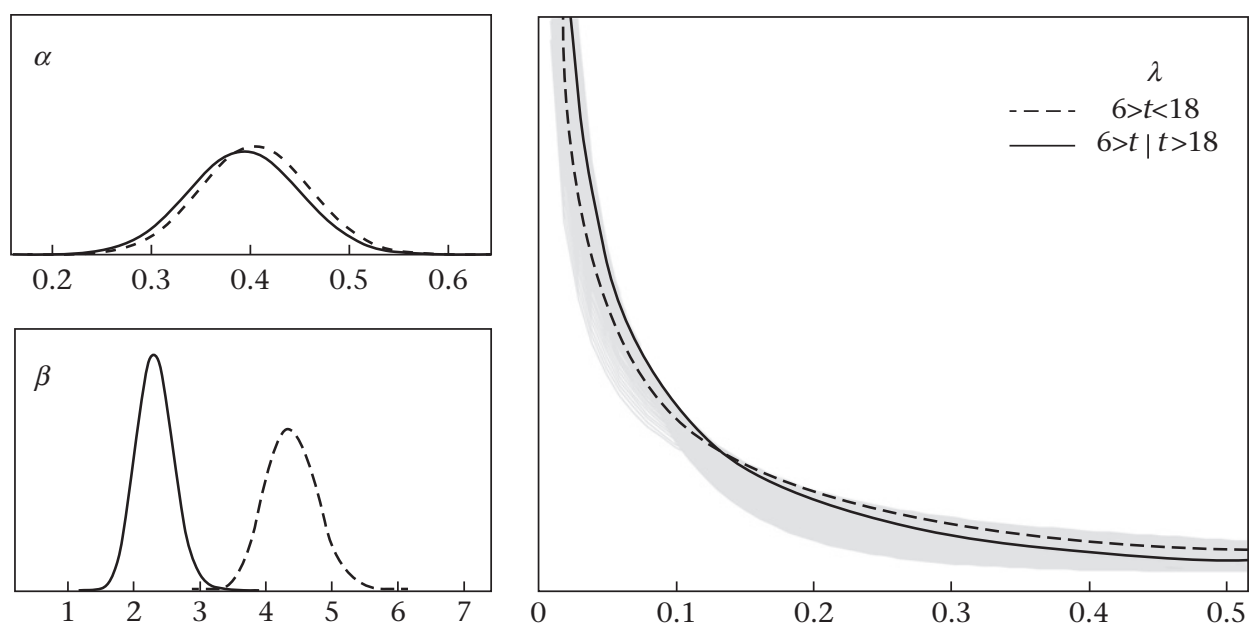

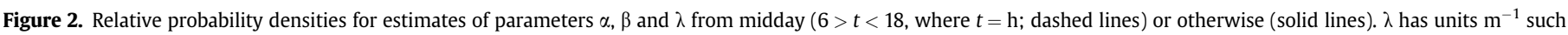
that larger $\lambda$ (dashed line) shortens the viewshed extent. 
Table 2

Estimates of parameters influencing the viewshed of locations chosen by lions grouped by behaviour and sex

\begin{tabular}{|c|c|c|c|c|c|c|c|c|c|c|c|c|}
\hline \multirow[t]{2}{*}{ Index } & \multicolumn{2}{|l|}{ Covariates } & \multirow[t]{2}{*}{$n$} & \multicolumn{2}{|l|}{$\alpha$} & \multicolumn{2}{|l|}{$\beta$} & \multirow[t]{2}{*}{$\beta / \alpha(\mathrm{m})$} & \multirow[t]{2}{*}{$\ln L$} & \multirow[t]{2}{*}{ LR } & \multirow[t]{2}{*}{ Dev } & \multirow[t]{2}{*}{$P$} \\
\hline & Behaviour & Sex & & Mean & $\mathrm{CI}$ & Mean & $\mathrm{CI}$ & & & & & \\
\hline 1 & $\mathrm{~B}$ & Both & 199 & 0.39 & $0.31-0.47$ & 3.13 & $2.03-4.55$ & 8.12 & -58155 & $1 /(2 \times 3)$ & 11 & $0.01^{*}$ \\
\hline 2 & $\mathrm{~K}$ & Both & 51 & 0.37 & $0.24-0.53$ & 2.24 & $0.86-4.52$ & 6.08 & -13640 & $1 /(4 \times 5)$ & 6 & 0.06 \\
\hline 3 & $\mathrm{R}$ & Both & 148 & 0.4 & $0.31-0.5$ & 3.75 & $2.34-5.58$ & 9.44 & -44510 & $4 /(6 \times 7)$ & 28 & $8 \mathrm{E}-07^{*}$ \\
\hline 4 & B & Male & 44 & 0.33 & $0.21-0.51$ & 2.79 & $0.88-6.03$ & 8.33 & -13986 & $5 /(8 \times 9)$ & 1 & 0.59 \\
\hline 5 & B & Female & 155 & 0.4 & $0.32-0.5$ & 3.33 & $2.16-4.85$ & 8.25 & -44159 & & & \\
\hline 6 & $\mathrm{~K}$ & Male & 11 & 0.35 & $0.14-0.7$ & 1.19 & $0.1-4.15$ & 3.43 & -2442 & & & \\
\hline 7 & $\mathrm{R}$ & Male & 33 & 0.41 & $0.24-0.65$ & 8.08 & $2.77-17.87$ & 19.61 & -11181 & & & \\
\hline 8 & $\mathrm{~K}$ & Female & 40 & 0.4 & $0.26-0.58$ & 3.41 & $1.35-6.78$ & 8.6 & -11538 & & & \\
\hline 9 & $\mathrm{R}$ & Female & 115 & 0.4 & $0.31-0.52$ & 3.36 & $2-5.19$ & 8.31 & -32962 & & & \\
\hline
\end{tabular}

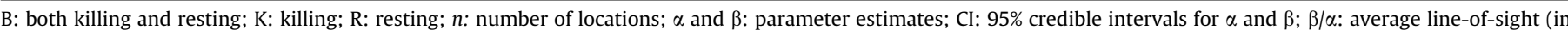

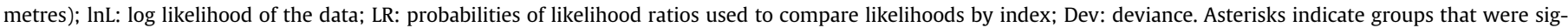
nificantly different.

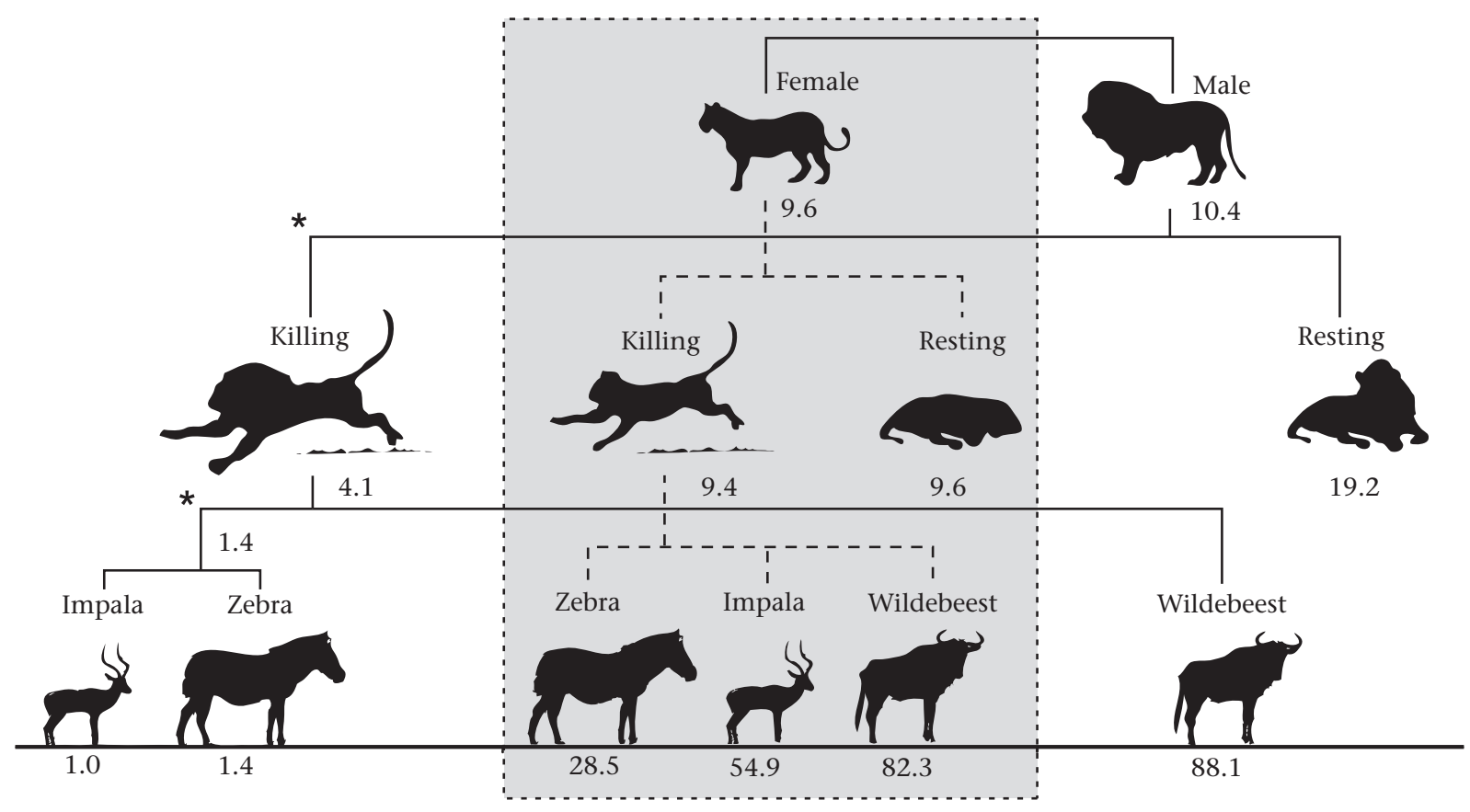

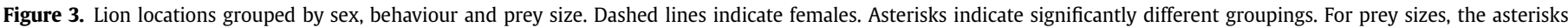
indicate significant differences between alternate subsets of kills by prey size and resting locations. Numbers are average line-of-site distances in metres.

that the benefits of hiding outweigh the risks of ambush. In contrast, Valeix et al.'s (2009) finding that both browsers and grazers prefer open areas when lions are nearby implies high ambush risks in dense vegetation. Our results suggest that these risks vary by both lion sex and prey choice. Male lions' ambush strategy makes dense vegetation a dangerous place for prey. In contrast, we found no influence of vegetation on female lion hunting choices. Studies have shown that forest habitat is safer from predation by wolves,

Table 3

Estimates of parameters influencing the viewshed of locations chosen by lions grouped by behaviour, sex and prey type

\begin{tabular}{|c|c|c|c|c|c|c|c|c|c|c|c|c|}
\hline \multicolumn{3}{|l|}{ Covariates } & \multirow[t]{2}{*}{$n$} & \multicolumn{2}{|l|}{$\alpha$} & \multicolumn{2}{|l|}{$\beta$} & \multirow[t]{2}{*}{$\beta / \alpha(\mathrm{m})$} & \multirow[t]{2}{*}{$\ln L$} & \multirow[t]{2}{*}{ LR } & \multirow[t]{2}{*}{ Dev } & \multirow[t]{2}{*}{$P$} \\
\hline Behaviour & Sex & Prey size & & Mean & $\mathrm{CI}$ & Mean & $\mathrm{CI}$ & & & & & \\
\hline $\bar{R}$ & Male & - & 33 & 0.41 & $0.24-0.65$ & 8.07 & $2.82-17.93$ & 19.61 & -11180 & $1 /(2 \times 3)$ & 27 & $2 \mathrm{E}-06^{*}$ \\
\hline B & Male & Small & 35 & 0.34 & $0.2-0.55$ & 3.88 & $0.91-9.21$ & 11.39 & -11479 & $1 /(4 \times 5)$ & 13 & $0.00^{*}$ \\
\hline K & Male & Small & 2 & 0.29 & $0.03-0.89$ & 1.67 & $0-12.65$ & 5.76 & -284 & $6 /(7 \times 8)$ & 5 & 0.09 \\
\hline B & Male & Large & 42 & 0.37 & $0.23-0.55$ & 4.24 & $1.56-8.9$ & 11.5 & -13343 & $6 /(9 \times 10)$ & 0 & 1.00 \\
\hline K & Male & Large & 9 & 0.37 & $0.14-0.79$ & 1.95 & $0.14-6.96$ & 5.22 & -2156 & & & \\
\hline $\mathrm{R}$ & Female & - & 115 & 0.4 & $0.31-0.51$ & 3.35 & $2-5.16$ & 8.29 & -32968 & & & \\
\hline B & Female & Small & 126 & 0.4 & $0.32-0.51$ & 3.35 & $2.05-5.11$ & 8.29 & -36064 & & & \\
\hline K & Female & Small & 11 & 0.4 & $0.16-0.79$ & 4.12 & $0.46-14.58$ & 10.43 & -3099 & & & \\
\hline B & Female & Large & 144 & 0.4 & $0.32-0.5$ & 3.33 & $2.11-4.91$ & 8.26 & -41400 & & & \\
\hline K & Female & Large & 29 & 0.39 & $0.23-0.61$ & 3.44 & $1.1-7.74$ & 8.79 & -8439 & & & \\
\hline
\end{tabular}

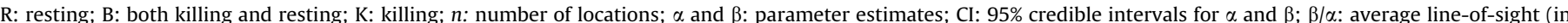

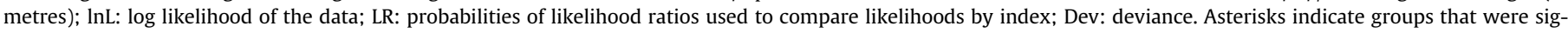
nificantly different. 
Canis lupus, than is the surrounding open landscape (Creel et al. 2005; Hernandez \& Laundre 2005), and it is likely that the bene-fits of hiding outweigh the risks of ambush by other cursorial predators such as wild dogs, Lycaon pictus. These results support the importance of landscape-scale vegetation structure in shaping predator-prey impacts (Lima \& Bednekoff 1999). By strongly linking male lion hunting behaviour to dense vegetation in our study, assuming that these behaviours are representative across lions elsewhere, our results suggest that changes to vegetation structure could likely cause changes in the balance of predators and prey where lions are present.

\section{Acknowledgments}

We thank Augusta Mabunda and Robert Dugtig for assistance in the GPS cluster investigations. The Kruger National Parks veterinarians Peter Buss and Danny Govender, as well as Marius Kruger are thanked for their time and effort in sedating and collaring lions. Support from the James S. McDonnell Foundation and a United States National Science Foundation Ecology of Infectious Disease Grant DEB-0090323 to Wayne Getz at the University of California, Berkeley, and a National Research Foundation grant to C.J. Tambling funded the collars and field component of the project. We thank D. Knapp for assistance with line-of-sight modelling, and T. KennedyBowdoin for LiDAR data processing. This study was supported by the Andrew Mellon Foundation. The Carnegie Airborne Observatory is made possible by the Gordon and Betty Moore Foundation, the Grantham Foundation for the Protection of the Environment, Avatar Alliance Foundation, W. M. Keck Foundation, the Margaret A. Cargill Foundation, Mary Anne Nyburg Baker and G. Leonard Baker, Jr and William R. Hearst, III.

\section{References}

van Aarde, R. J. \& Jackson, T. P. 2007. Megaparks for metapopulations: addressing the causes of locally high elephant numbers in southern Africa. Biological Conservation, 134, 289-297.

Asner, G. P., Knapp, D. E., Jones, M. O., Kennedy-Bowdoin, T., Martin, R. E., Boardman, J. \& Field, C. B. 2007. Carnegie Airborne Observatory: in-flight fusion of hyperspectral imaging and waveform light detection and ranging for three-dimensional studies of ecosystems. Journal of Applied Remote Sensing, 1, 013536.

Asner, G. P., Levick, S. R., Kennedy-Bowdoin, T., Knapp, D. E., Emerson, R. Jacobson, J., Colgan, M. S. \& Martin, R. E. 2009. Large-scale impacts of herbivores on the structural diversity of African savannas. Proceedings of the $\mathrm{Na}$ tional Academy of Sciences, U.S.A., 106, 4947-4952.

Bengtsson, J., Angelstam, P., Elmqvist, T., Emanuelsson, U., Folke, C., Ihse, M. Moberg, F. \& Nyström, M. 2003. Reserves, resilience and dynamic landscapes. AMBIO: A Journal of the Human Environment, 32, 389-396.

Berger, J. 2004. The last mile: how to sustain long-distance migration in mammals. Conservation Biology, 18, 320-331.

Biggs, H., Rogers, K. \& Du Toit, J. 2003. The Kruger Experience: Ecology and Management of Savanna Heterogeneity. Washington, D.C.: Island Press.

Ceballos, G., Ehrlich, P. R., Soberon, J., Salazar, I. \& Fay, J. P. 2005. Global mamma conservation: what must we manage? Science, 309, 603.

Clark, J. S. 2005. Why environmental scientists are becoming Bayesians. Ecology Letters, 8, 2-14.

Clark, J. 2006. Models for Ecological Data. Princeton, New Jersey: Princeton University Press

Clark, J. S. \& Gelfand, A. E. 2006. A future for models and data in environmental science. Trends in Ecology \& Evolution, 21, 375-380.

Creel, S., Winnie, J., Maxwell, B., Hamlin, K. \& Creel, M. 2005. Elk alter habitat selection as an antipredator response to wolves. Ecology, 86, 3387-3397.

Davies, S. J. J. F. \& Bertram, B. C. R. 2003. Ostrich. In: Firefly Encyclopedia of Birds (Ed. by C. Perrins), pp. 34-37. Buffalo, New York: Firefly Books.

Elliott, J. P., Cowan, I. M. \& Holling, C. S. 1977. Prey capture by the African lion. Canadian Journal of Zoology, 55, 11.

Ferreira, S. M. \& Funston, P. J. 2010. Estimating lion population variables: prey and disease effects in Kruger National Park. South Africa Wildlife Research, 37, 194206.

Fischhoff, I. R., Sundaresan, S. R., Cordingley, J. \& Rubenstein, D. I. 2007. Habitat use and movements of plains zebra (Equus burchelli) in response to predation danger from lions. Behavioral Ecology, 18, 725-729.
Funston, P., Mills, M., Biggs, H. \& Richardson, P. 1998. Hunting by male lions: ecological influences and socioecological implications. Animal Behaviour, 56, 1333-1345.

Funston, P. J., Mills, M. G. L. \& Biggs, H. C. 2001. Factors affecting the hunting success of male and female lions in the Kruger National Park. Journal of Zoology, 253, 419-431.

Gelman, A., Carlin, J. B., Stern, H. S. \& Rubin, D. B. 1995. Bayesian Data Analysis. London: Chapman \& Hall.

Grant, C. C., Davidson, T., Funston, P. J. \& Pienaar, D. J. 2007. Challenges faced in the conservation of rare antelope: a case study on the northern basalt plains of the Kruger National Park. Koedoe-African Protected Area Conservation and Science, 45, 45-66.

Hay, C. T., Cross, P. C. \& Funston, P.J. 2008. Trade-offs of predation and foraging explain sexual segregation in African buffalo. Journal of Animal Ecology, 77, 850-858.

Hayward, M. W. \& Kerley, G. I. H. 2005. Prey preferences of the lion (Panthera leo). Journal of Zoology, 267, 309-322.

Hayward, M. W. \& Slotow, R. 2009. Temporal partitioning of activity in large African carnivores: tests of multiple hypotheses. South African Journal of Wildlife Research, 39, 109-125.

Hayward, M. W. \& Somers, M. J. 2009. Reintroduction of Top-order Predators: Using Science to Restore One of the Drivers of Biodiversity. Oxford: Blackwell.

Hayward, M., O'Brien, J., Hofmeyr, M. \& Kerley, G. 2007. Testing predictions of the prey of lion derived from modeled prey preferences. Journal of Wildlife Management, 71, 1567-1575.

Hernandez, L. \& Laundre, J. W. 2005. Foraging in the 'landscape of fear' and its implications for habitat use and diet quality of elk Cervus elaphus and bison Bison bison. Wildlife Biology, 11, 215-220.

Hopcraft, J. G. C., Sinclair, A. R. E. \& Packer, C. 2005. Planning for success: Serengeti lions seek prey accessibility rather than abundance. Ecology, 74, 559-566.

Hutton, J. M. \& Leader-Williams, N. 2003. Sustainable use and incentivedriven conservation: realigning human and conservation interests. Oryx, 37, 215-226.

Karanth, K. K., Nichols, J. D., Karanth, K. U., Hines, J. E. \& Christensen, N. L., Jr. 2010. The shrinking ark: patterns of large mammal extinctions in India. Proceedings of the Royal Society B, 277, 1971-1979.

Lefsky, M., Harding, D., Cohen, W., Parker, G. \& Shugart, H. 1999. Surface lidar remote sensing of basal area and biomass in deciduous forests of eastern Maryland, USA. Remote Sensing of Environment, 67, 83-98.

Levick, S. R., Asner, G. P., Kennedy-Bowdoin, T. \& Knapp, D. E. 2009. The relative influence of fire and herbivory on savanna three-dimensional vegetation structure. Biological Conservation, 142, 1693-1700.

Lima, S. L. \& Bednekoff, P. A. 1999. Temporal variation in danger drives antipredator behavior: the predation risk allocation hypothesis. American Naturalist, 153, 649-659.

Lindsey, P. A., Alexander, R., Mills, M. G. L., Romanach, S. \& Woodroffe, R. 2007. Wildlife viewing preferences of visitors to protected areas in South Africa: implications for the role of ecotourism in conservation. Journal of Ecotourism, $\mathbf{6}$, 19-33.

Loarie, S. R., van Aarde, R. J. \& Pimm, S. L. 2009a. Fences and artificial water affect African savannah elephant movement patterns. Biological Conservation, 142, 3086-3098

Loarie, S. R., van Aarde, R. J. \& Pimm, S. L. 2009b. Elephant seasonal vegetation preferences across dry and wet savannas. Biological Conservation, 142, 3099-3107.

Mills, M. G. L. \& Biggs, H. C. 1993. Prey apportionment and related ecological relationships between large carnivores in Kruger National Park. Symposium of the Zoological Society of London, 65, 253-268.

Owen-Smith, N. \& Mills, M. G. L. 2006. Manifold interactive influences on the population dynamics of a multispecies ungulate assemblage. Ecological Monographs, 76, 73-92.

Owen-Smith, N. \& Mills, M. G. L. 2008. Predator-prey size relationships in an African large-mammal food web. Journal of Animal Ecology, 77, 173-183.

Radloff, F. G. T. \& Du Toit, J. T. 2004. Large Predators and their prey in a southern African savanna: a predator's size determines its prey size range. Journal of Animal Ecology, 73, 410-423.

Ripple, W. J. \& Beschta, R. L. 2006. Linking a cougar decline, trophic cascade, and catastrophic regime shift in Zion National Park. Biological Conservation, 133 397-408.

Schaller, G. B. 1972. The Serengeti Lion. Chicago: University of Chicago Press.

Scheel, D. \& Packer, C. 1991. Group hunting behaviour of lions: a search for cooperation. Animal Behaviour, 41, 697-709.

Sinclair, A. R. E., Mduma, S. \& Brashares, J. S. 2003. Patterns of predation in a diverse predator-prey system. Nature, 425, 288-290.

Sinclair, A. R. E., Pech, R. P., Dickman, C. R., Hik, D., Mahon, P. \& Newsome, A. E. 2008. Predicting effects of predation on conservation of endangered prey. Conservation Biology, 12, 564-575.

Slotow, R. \& Hunter, L. T. B. 2009. Reintroduction decisions taken at the incorrect social scale devalue their conservation contribution: African lion in South Africa. In: The Reintroduction of Top-order Predators (Ed. by M. W. Hayward \& M. Somers), pp. 43-71. Oxford: Blackwell.

Smith, F. A., Lyons, S. K., Ernest, S. K. M., Jones, K. E., Kaufman, D. M., Dayan, T., Marquet, P. A., Brown, J. H. \& Haskell, J. P. 2003. Body mass of late Quaternary mammals. Ecology, 84, 3403.

Smuts, G. L., Whyte, I. J. \& Dearlove, T. W. 1977. A mass capture technique for lions. East African Wildlife Journal, 15, 81-87. 
Stander, P. E. 1992. Cooperative hunting in lions: the role of the individual. Behavioral Ecology and Sociobiology, 29, 445-454.

Tambling, C. J. \& Du Toit, J. T. 2005. Modelling wildebeest population dynamics: implications of predation and harvesting in a closed system. Journal of Applied Ecology, 42, 431-441.

Tambling, C. J., Cameron, E. Z., Du Toit, J. T. \& Getz, W. M. 2010. Methods for locating African lion kills using global positioning system movement data. Journal of Wildlife Management, 74, 549-556.
Valeix, M., Loveridge, A. J., Chamaille-Jammes, S., Davidson, Z., Murindagomo, F., Fritz, H. \& Macdonald, D. W. 2009. Behavioral adjustments of African herbivores to predation risk by lions: spatiotemporal variations influence habitat use. Ecology, 90, 23-30.

Woodroffe, R. \& Ginsberg, J. R. 1998. Edge effects and the extinction of populations inside protected areas. Science, 280, 2126-2128.

Wronski, T., Apio, A. \& Plath, M. 2006. Activity patterns of bushbuck (Tragelaphus scriptus) in Queen Elizabeth National Park. Behavioural Processes, 73, 333-341. 